\title{
New Resonance Approach to Competitiveness Interventions in Lagging Regions: The Case of Ukraine before the Armed Conflict
}

\section{Roman Guliak ${ }^{1}$}

\begin{abstract}
Regional competitiveness is considered to be an alternative basis for the determination of regional interventions. However, the composite competitiveness indicator is quite sensitive to the weights of sub-indicators, no matter what methodology is being used. To avoid this uncertainty in the determination of regional interventions, we proposed a new non-compensatory resonance approach that is focused on the hierarchical coincidence between weaknesses of NUTS 1 and NUTS 2 regions measuring the extensive and intensive components of competitiveness. Such a coincidence, being perceived as a resonance effect, is supposed to increase the effectiveness of interventions triggering synergetic effects and stirring up local regional potentials. The components of competitiveness are obtained through synthesising DEA methodology and Hellwig's index, correspondingly focusing on the measurement of technical efficiency and resource level. In analysing Ukrainian regions, no correlation between resonance interventions and the composite competitiveness indicator or GDP per capita was found, pointing toward a completely different direction in resonance approach. In western Ukraine, the congestion of six NUTS 2 regions was defined as a homogeneous area of analogous resonance interventions focused on improving business efficiency.
\end{abstract}

Key words: Regional competitiveness, Resonance interventions, Weakness coincidence, Resource level, Efficiency, DEA, Hellwig's indicator

JEL Classification: O47, R11, R58, R15

Received: 4 March 2016/Accepted: 25 February 2017/Sent for Publication: 21 March 2017

\section{Introduction}

The increasing popularity of regional competitiveness (RC) in the last decades has brought this concept to the forefront, overtaking the previously fashionable GDP indicator. This race has recently generated a large amount of research on the topic, creating a new alternative basis for regional policy. Indeed, as an advanced analogy of GDP, RC appears to be a good measure of regional performance and is able to present new perspectives of regional development more comprehensively using the composite competitiveness indicator (CI). One group of authors (Annoni, Dijsktra, 2013; Annoni, Dijsktra, Kozovska, 2011; Annoni, Kozovska, 2010; Gábor, Ottaviano, 2015; Hollanders, Tarantola, Loschky, 2009; Huggins, 2003, 2006; Huggins, Thompson,

\footnotetext{
${ }^{1}$ VŠB - TU Ostrava, Faculty of Economics, Sokolská třída 33, 70121 Ostrava 1, Czech Republic, e-mail: roman.guliak@vsb.cz

(c) 2017 by the authors; licensee Review of Economic Perspectives / Národohospodářský obzor, Masaryk University, Faculty of Economics and Administration, Brno, Czech Republic. This article is an open access article distributed under the terms and conditions of the Creative Commons Attribution 3.0 license, Attribution - Non Commercial - No Derivatives.
} 
2010; Huovari, Kangasharju, Alanen, 2001; Snieška, Bruneckienė, 2009; UNDP, 2008) prefers the use of synthetic methods based on a linear aggregation. The other group is in favour of MCDM methods, in particular ELECTRE (Oliva, Miguel, 2005; Fernandez, Navarro, 2013), AHP (Nevima, Ramík, 2009; Kiszová, Nevima, 2012) and DEA (Melecký, Staníčková, 2011; Ramík, Hančlová, 2012; Charles, Zegarra, 2014).

From a policy-making perspective, the usefulness of CI is limited to choosing "winners and losers", where the last ones are subject to the policy interventions. The recipe is simple: the more lagging a region is, the more "medicine" it requires. This is obviously the simplest rule, making competitiveness usable for regional policy makers. However, such a simple approach, no matter which aggregating technique has been used, does not pay attention to the following spatial and hierarchical specifics while determining the targets. As there is a significant spatial correlation between neighbouring NUTS 2 regions, the corresponding NUTS 1 regions can considerably influence their performance. This means that paying attention to the hierarchical interconnectedness of NUTS 1 and included NUTS 2 regions while establishing the target can lead to important synergetic effects. Therefore, the more complex the system we investigate, the more differential the approach to its characteristics should be applied for policymaking, instead of just an aggregation procedure leading to the composite CI.

Stepping away from the mentioned oversights, the main purpose of this paper is to propose a new resonance approach to determining regional policy interventions. This approach is based on the measurement of extensive and intensive dimensions of competitiveness and considers hierarchical dependency represented by the coincidence of weaknesses between NUTS 1 and NUTS 2 regions. Having applied this approach, it will be possible to determine the neighbouring congestion of lagging Ukrainian NUTS 2 regions with like-oriented interventions causing a synergetic effect and leading not only to a decrease in inequalities, but also to a common release of local development potentials.

Another factor decreasing the usefulness of competitiveness for the policy makers is a poly-pillar compensatory measurement approach using a single methodology. Pillars encompassing basic indicators should be clearly structured and precisely reflect areas of diagnosis representing the essence of the competitiveness. Otherwise, in the case of developing countries, regional performance and competitiveness should be based mostly on business and labour (working) factors, which allow for decreasing the number of essential pillars included in an analysis. That is why we decided to focus on the simplified and, at the same time, clear "magnetic" vision of competitiveness. In accordance with this vision, Annoni and Dijkstra (2013) define RC as "the ability to offer an attractive and sustainable environment for firms and residents to live and work." The "magnetic" view, meaning that a competitive region literally attracts human capital and businesses, is supported by a great number of definitions and descriptions of competitiveness (Poot, 2000; Cooke, 2004; Porter and Ketels's definition, 2003; Storper, 1997; Aiginger, K., 2006; Pessoa A., 2013). It should be noted that while RC has been measured in different ways, the "magnetic" perception has remained only as a definition and has not been quantified. Moreover, in our opinion, such a poly-dimensional phenomenon as RC should be analysed based on the synthesis of methods specifically suited to each dimension being explored. 
The secondary aim of this paper is to measure competitiveness based on its attractive nature in the context of two dimensions different in principle, namely extensive (resource level) and intensive (technical efficiency), using a poly-methodological basis and aspects (pillars) reflecting the performance of human and business capital, as direct "consumers" of competitiveness. To uncover the extensive dimension, we aggregate initial inputs with the distant method (Hellwig, 1968), using a synthetic indicator to measure the level of regional resources (extensive component). The DEA method (Charnes, Cooper, Rhodes, 1978) is focused on the technical efficiency of the region and aggregates inputs and outputs (outcomes) reflecting the intensive dimension of competitiveness. To our knowledge, DEA and Hellwig's indices have never been combined in similar studies to investigate these dimensions.

All calculations applied for the Ukrainian regions use data from 2013 - the last year before the escalation of the armed conflict with Russia and the separation of the Crimea, Donecky and Lugansky regions. The paper consists of the following sections: theoretical framework, methodology, application of the methods, conclusion.

\section{Theoretical framework}

\subsection{The basic concept of the resonance approach}

The core of the resonance approach can be formulated in the following way: if the weaknesses of lagging NUTS 2 regions coincide with corresponding NUTS 1 regions and other neighbouring NUTS 2 regions, such a homogeneous area requires resonance homogeneous interventions forming a synergetic effect in their regional performance. Simply put, this approach relies on the "weakness coincidence" as the base for policymaking. Regional weakness is defined as the explored composite characteristic presented as a component of competitiveness (sub-indicator) that has been ranked as the worst compared to other characteristics within the same region. For the sake of formalization, we provide definitions of the interventions analysed further:

a) resonance interventions (RI) assume hierarchical coincidence between NUTS 1 and included NUTS 2 regional weaknesses.

b) homogeneous RI imply not only hierarchical but also spatial coincidence of weaknesses between NUTS 2 and corresponding NUTS 1 regions. In other words, the synergy effect caused by these interventions is based on the double weakness coincidence defined in spatial and hierarchical form.

c) ordered RI presuppose a series of consecutive RI, based on double coincidence and strict succession of ranks.

The combined effect of homogeneous RI based on territorial synergy will be greater than interventions elaborated for each region in isolation. Simply said, what is profitable for a NUTS 2 region should also be a priority for the system (NUTS 1 region). No region has enough potential to realize a maximum positive effect while in horizontal (between NUTS 2 regions) or hierarchical (NUTS 2 and NUTS 1) isolation. 


\subsection{Assumptions and hypotheses}

The rationale of the suggested resonance intervention approach is based on the following assumptions revealing the cornerstones of the framework. As the paper has two aims, we divide assumptions into two blocks. The first three assumptions are about the particularities of competitiveness measurement and the three final ones directly relate to the resonance approach:

1) the set of pillars is based on the "magnetic vision of RC." In particular, the number of pillars is reduced to human capital, business and meso-level. These pillars describe the performance of the two main consumers of $\mathrm{RC}$, those that primarily form competitiveness in the developing countries;

2) pillars are measured from a two-dimension perspective following input and output division, in particular, intensive (technical efficiency) and extensive (resource level);

3) aspects (pillars) and dimensions are the same at both NUTS 1 and NUTS 2 hierarchical levels. The fractal principle is adhered to as the basic underlying principle. It simplifies the competitiveness benchmarking at NUTS 1, 2 levels, keeping the composition of components scale-free (similar);

4) the NUTS 1 division of the country is assumed to be a functional division;

5) in lagging regions, policy interventions focus on the "weak link," or the regional weakness that, when dealt with, represents a trigger for competitiveness improvements and local potential realization;

6) the efficiency of policymaking focused on lagging regions can be increased with homogeneous RI.

The last assumption is highlighted and justified from several points of view in the next section. Below, we present the set of hypotheses, which are fully consistent with the introduced types of interventions. The set is made up of the following hypotheses: determination of RI by the level of total competitiveness (A), determination of RI by the components of competitiveness (B), the presence of a homogeneous (C) and ordered area of RI (D).

A. $\mathrm{H}_{0}$ : RI to the NUTS 2 regions are not determined by their level of total competitiveness or economic development (GDP/capita).

$\mathrm{H}_{\text {alt. }}$ : RI to the NUTS 2 regions are determined by competitiveness.

B. $\mathrm{H}_{0}$ : RI to the NUTS 2 regions are not determined by the level of competitiveness components.

$\mathrm{H}_{\text {alt. }}$ : RI to the NUTS 2 regions are determined by competitiveness components.

C. $\mathrm{H}_{0}$ : there are no equal RI to the regions neighbouring to each other.

$\mathrm{H}_{\text {alt. }}$ : there is a homogeneous area (spatial coincidence) of RI targeted at neighbouring NUTS 2 regions.

D. $\mathrm{H}_{0}$ : there are no consecutively ranked $\mathrm{RI}$ in the homogeneous area.

$\mathrm{H}_{\text {alt. }}$ : RI in the homogeneous area are ranked in a series.

Al hypotheses will be tested in subsection 4.3. 


\subsection{Argumentation of resonance approach}

In this section, the last assumption about the effectiveness of RI is justified in terms of a systemic approach, territorialisation philosophy and equity-efficiency trade-off. Taking all these points of view into consideration gives some evidence that RI are able to improve a regional policymaking process when attention is paid to the hierarchical regional structure.

The first argument is based on emergence - the reason for an inevitable lack of complex system comprehensiveness. An emergent property is being understood as a synthesis of synchronization and the synergetic effect. In territorial systems, the synergetic effect increases due to regional interactions, which themselves can be significantly impacted by effective policy interventions representing the synchronization component. Synchronization especially should be the first concept underlying regional improvements. Referring to Luhmann's statement about system nature, regions are considered super complex social and economic systems. His idea is that being a system is not an inherent property for any complex object, but, in contrast, it is an extrinsic characteristic of the structure (N. Luhmann, 2002). The uniqueness of the system becomes apparent only in interactions with an external environment. Thereby an extrinsic systemic characteristic of a country can be fully uncovered only through the consideration of a regional hierarchical structure determining regional interactions. The same works when considering the RC of a NUTS 2 region, which can be revealed only by taking into account characteristics of the included NUTS 1 system:

$$
C_{i}=\left\langle C_{i} ; Q_{s} ; R\right\rangle \text {, when } Q_{s} \neq \sum_{i=1}^{n} q_{i},
$$

where: $Q_{s}$ - emergence, $q_{i}$ - components of a system, $C_{\mathrm{i}}-$ competitiveness of a NUTS 2 region; $C_{s}$ - competitiveness of a system (NUTS 1 or country); $R$ - relations between regions.

The following reference point for RI stems from the perspective that modern regional development needs to be governed in the frame of "territorialisation" philosophy. (Harmaakorpi, 2006; Cooke, 2007). We wholly share the idea of close matching of and full integration between new development projects and the local realm, at the same time mobilizing multiple local resources on a wide area in synergy with public action (Camagni, 2011). The concept of "territorial platforms" could help elaborate policy interventions acting on multiple dimensions in an integrated nature, suggesting and supporting potential complementarities between different actions and goals (Camagni, Capello, 2014). Built upon it, according to the target establishment context, we apply the concept of "territorial platforms" as "target platforms," implying the coincidence of targets on both hierarchical (NUTS 1 and NUTS 2) and horizontal (spatial contiguity) levels. RI based on such a coincidence are considered more effective due to the synchronization effect coming alive in the policymaking.

Another justification for the usefulness of the resonance principle can be found by referring to the famous and perhaps old-fashioned (Camagni R., Capello R., 2014) trade-off between the effectiveness and equity of regional policy interventions. The efficiency-equity trade-off discussion was started by Perroux (1955), Kuznets (1955), Myrdal (1957), et al., and has been deepened recently by contemporary scientists such 
as Martin (1999, 2001), Ottavino (2001), Puga (2002), Midelfart (2004), Meyer (2005), which rely on the combined platform of new economic geography and the theory of endogenous growth. Returning to the importance of synchronization in an emergent property, the synchronization of elements focuses on target establishment, paying attention to the interaction of hierarchical levels. At this stage, we are hampered by conflicts between different hierarchical levels. On the highest country level, primary importance is assigned to economic effectiveness, where growth of agglomerations with a high concentration of labour, capital and knowledge in the most developed regions is the strongest factor. Meanwhile, locally, the prosperity of each region and high living standards are regarded as having paramount importance. When formulating a strategy the question is whether to establish basic targets that benefit the country development or support lagging regions leading to an even development. The way to decrease the conflict and make these two extremes work together as an entire system is simply to introduce a middle point - the third hierarchical NUTS 1 level presenting congestions (subsystems), or rather functional regions (fig. 1).

Figure 1. Relationships between equity and economic efficiency according different targets

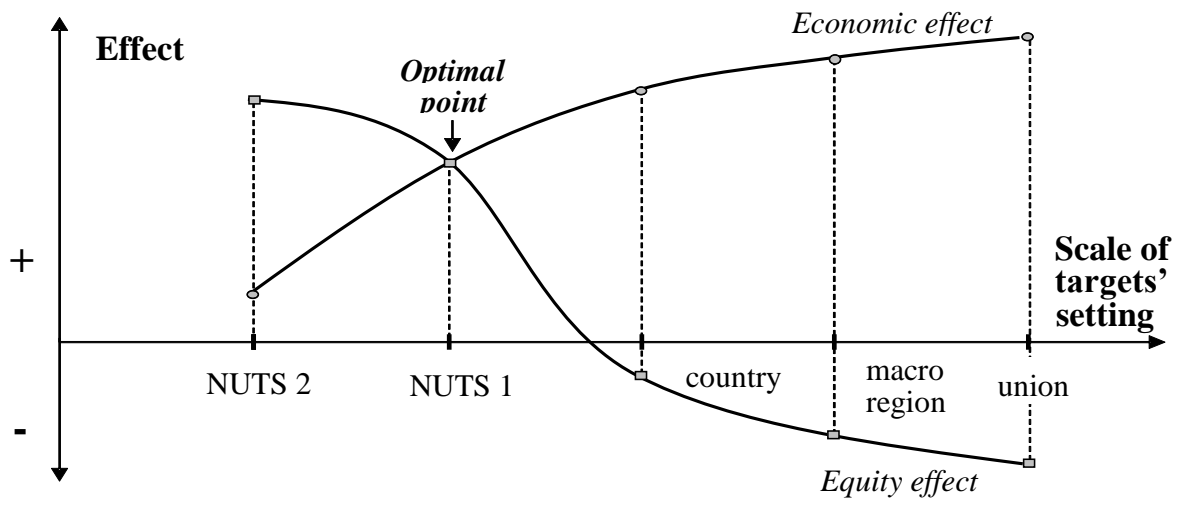

Source: author

From this figure, we can conclude that there are two basic approaches: bottom-up leading to equalize the regional development, and top-down - increasing the level of concentration of factors and accelerating economic growth. The crossing optimal point tells us that NUTS 2 regions, whose basic targets coincide with the development priorities of NUTS 1 regions, are to some extent able to balance the economic performance of a country, partially reaching both economic efficiency and equity. Spending all resources on targets unable to improve the higher sub systematic (NUTS 1) level is nothing but ineffective when compared to another approach that reaches targets on both hierarchical levels at the same time. The development orientation of a NUTS 1 region will dominate the process of selecting targets. The coincidence of targets itself triggers a resonance effect that makes positive synergetic influence on both NUTS 1 as a whole and on its constituent NUTS 2 regions. Describing a fully hierarchical synchronization and selection process of possible interventions, figure 2 shows components of an extended target vector for three benchmarking levels (NUTS 2, NUTS 1, country). 
Figure 2. Target selecting process

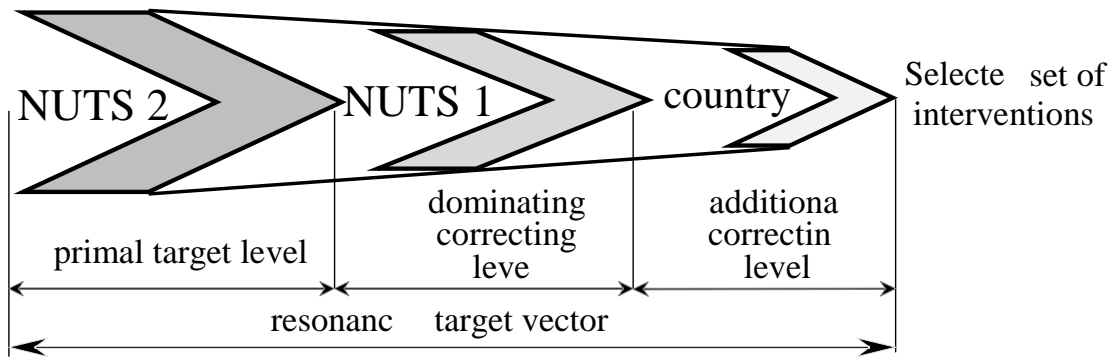

Source: author

The eventually selected targets satisfy the interests of both NUTS levels and make a greater contribution to the country development than could be achieved by orientating only on primal NUTS 2 targets. Paraphrasing, what is best for NUTS 2 regions also needs to be beneficial for NUTS 1 regions.

\subsection{Aspects of regional competitiveness policy}

From a practical point of view, the best way to show the essential link between competitiveness and policy making will be to simultaneously outline three essential aspects describing competitiveness interwoven into a policy making process (fig. 3 ).

Figure 3. Regional competitiveness policy aspects

Source: author

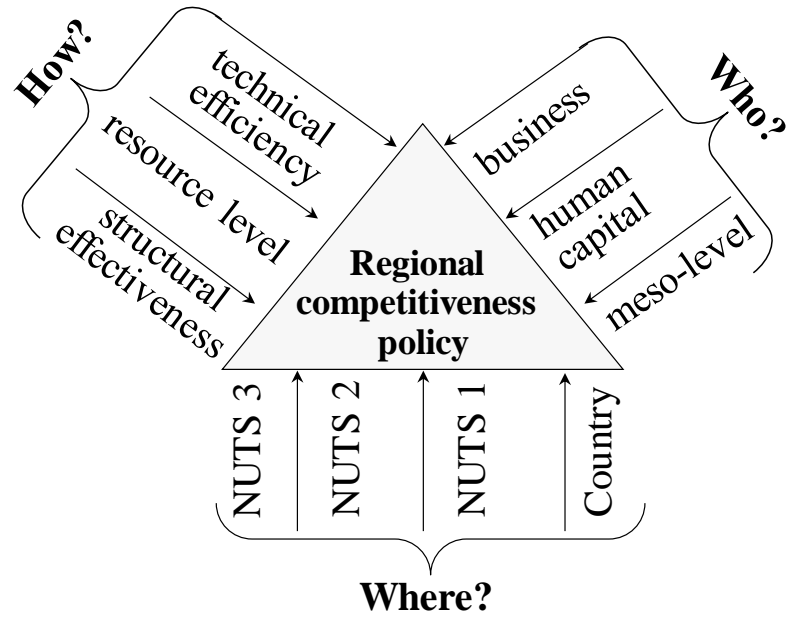

The first aspect answers the question: "Who is the recipient of RC disadvantages or benefits?" Correspondingly, receiving actors are the subjects of the most urgent policy interventions. Following the "magnetic" view, competitiveness is apprehended as a "magnet" of investment, capital, labour, knowledge and innovations - all necessary factors of regional growth. A great number of definitions and descriptions of 
competitiveness (Poot, 2000; Cooke, 2004; Porter and Ketels's definition, 2003; Storper, 1997; Aiginger, K., 2006; Tetsuya, Matsumoto, 2010; Pessoa A., 2013) support such view. Supporting competitive business and a good work environment will attract and retain highly skilled labour, impeding people and firms from draining to the outside (Pessoa, 2013, Florida, 2002). Paraphrasing, RC is focused on attracting and providing better conditions for businesses and the population - consequently, it is reasonable to concentrate on different groups of actors interested in a certain level of competitiveness. Consequently, activity of these groups could also be a proxy for measuring competitiveness. That is why we suggest measuring competitiveness in the light of three groups, which benefit from $\mathrm{RC}$ and reflect it: human capital (labour) interests, business interests and general meso-level group of regional or community interests.

The "magnetic" essence of competitiveness can be deemed clarified, but the composition of each group's abilities to attract still has not been. Applying philosophical and logical analysis, any ability underlying possible system performance directly depends on two integrated parts: an attributive (resource) part, namely resource amount presented as inputs, and a second situational part related to the conditions of resource usage (operating and developing conditions). This situational aggregated part of abilities comprises all factors, which are hard to measure (including "hard" and "soft" regional infrastructure) and which predetermine a technical efficiency of inputs usage. Double division of regional abilities allows us to build a simplified double-based approach for the competitiveness analysis. Separate estimation of the outputs does not have any value because both resources and outputs are used to estimate efficiency. Thus, the situational part can be explored by total multi factor productivity of the region. As Pessoa A. (2013) states: "looking only to productivity can be misleading: a high productivity of labour can result from reductions in employment by, for instance, shutting down plants". That is why our vision of competitiveness is not limited only by productivity, but supplemented with the level of regional resources.

The next aspect is: "Which methodology to use for RC measurement?" The answer, in our opinion, should be based on methodological pluralism (Flood and Jackson, 1991; Jackson, 1991; Flood and Romm, 1996; Mingers and Gill, 1997). The wider the range of available methods, the more flexible and responsive our systemic practice can be. No single methodology can make a comprehensive analysis of phenomena, especially when it comes to be RC. Therefore, being able to draw upon multiple methods from different paradigmatic sources can enhance the system's thinking resource we have available for intervention (Midgley G., 2014). To measure RC in different dimensions, we use three methods dealing with input and output categories. More methodological details are given in the subsequent section. The last aspect is "What is the best place or territory (region) for receiving the interventions?" The rationale of the answer to this question was explained in the previous subsections, where we reached the following conclusion about RI and the importance of the coincident of the intervention targets between NUTS 1 and NUTS 2 levels.

\section{Methodology of the competitiveness measurement}

Following the analysis of the first resource component, we get answers to the question: "What does a region perform with?" The second technical efficiency component helps 
answer the question: "Is regional performance efficient enough to produce maximum outputs from the given quantity of inputs?" Finally, the third structural effectiveness component offers an answer to the question: "Is a way of performance effective enough to produce indented or expected results?" This set of dimensions through which competitiveness is going to be studied requires corresponding methodological tools. All methods used in this paper are in compliance with the theoretical framework of RC investigation and reflect the specific traits of the highlighted dimensions.

\subsection{Data envelopment analysis of technical efficiency}

To evaluate the technical efficiency of resources usage, we apply a nonparametric method such as Data Envelopment Analysis (DEA), which was introduced by Charnes, Cooper, and Rhodes (1978). This method allows measuring the intensive dimension of RC. The backbone of the DEA methodology is linear programming based on an optimization platform. DEA models can generate new alternatives to improve performance compared to other techniques. The aim of this method is to divide regions into effective and non-effective ones by the amount of consumed inputs and produced outputs and finally, to obtain the respective efficiency coefficients for each region. The efficiency coefficient is the ratio between the weighted sum of outputs and the weighted sum of inputs. Armed with two basic DEA models (input or output oriented), it is worth mentioning that regional level efficiency could more likely be achieved by growing outputs than by decreasing inputs (Schaffer et al., 2011). We share this position, adding that economical resources in a regional should not be decreased, and vice versa, regions should try to create larger resource abilities in order to expand markets and be more influential economically. Following this point of view, a multiplier output-oriented model with a constant return to scale (CCR) is used:

$$
\begin{gathered}
\min q=\sum_{i=1}^{m} v_{i} x_{i 0,} \\
\text { s.t.: } \sum_{i=1}^{m} v_{i} x_{i j},-\sum_{r=1}^{s} \mu_{r} y_{r j} \geq 0, \quad \mu_{r}, v_{i}>0 . \\
\sum_{r=1}^{s} \mu_{r} y_{r j}=1,
\end{gathered}
$$

where $o-$ is the region being evaluated;

$s$ - number of outputs, $r=1,2 \ldots s$;

$m$ - number of inputs, $i=1,2 \ldots m$;

$y_{r-}$ the amount of output $r$ from region $j$;

$x_{i j}$-the amount of input $i$ from region $j$;

$\mu_{r}$ and $v_{i}$ are the weights given to output $r$ and input $i$, respectively.

When the number of regions is greater than the number of outputs, a dual model is used for computational reasons, giving efficiency scores from 0 to 1 . However, this method suffers from one serious limitation related to the necessity of having large enough numbers of DMUs to get a well-differentiated efficiency score. According to a "rule of 
thumb," the number of Ukrainian regions (26) is not sufficient concerning the initial number of inputs and outputs (9). To solve this problem, a taxonomy method was used to aggregate all inputs into one synthetic index.

\subsection{Numerical taxonomy analysis of resource level}

The next component of competitiveness is the resource level, which expresses the quality level of disposal resources. All regional resources can be characterized by a great number of features expressed by different indicators. For this purpose, we need to choose an appropriate method able to reduce the space of indices comprising all resource attributes into one composite indicator. Eventually, RC will be measured from an extensive point of view for each of the groups. In this research, we decided to use numerical taxonomy to estimate and categorize the development level of Ukrainian regions.

The Numerical Taxonomy Analysis assessing or measuring the degree of development in regions is aimed at detecting homogenous groups (Harman, H.H., 1976; Hellwig, Z., 1968; Pluta W., 1977) using Hellwig's synthetic indicator. Within this methodology using the principle of shortest (taxonomical) distance of an ideal object, we calculate the coefficients describing the development of resources belonging to the analysed regions. The introduced method is made up of these steps:

1. to form an initial matrix of data and to normalize it:

$$
Z_{i k}=\left(x_{i k}-\bar{x}_{k}\right) / S_{k},
$$

where: $x_{i k}-k^{\text {th }}$ attribute of the $i^{\text {th }}$ region.

$i=1,2, \ldots, \mathrm{w}$ (number of regions);

$k=1,2, \ldots, n$ (number of attributes);

$Z_{i k}$-normalized value of the $k^{\text {th }}$ variable in the $i^{\text {th }}$ region.

2. to determine an etalon $E o\left(Z_{01} \ldots Z_{0 n}\right)$ in accordance with the min-max criterion;

3. to calculate the matrix of distances from the etalon:

$$
c_{i o}=\left[\sum_{s=1}^{n}\left(z_{i k}-z_{o s}\right)^{2}\right]^{1 / 2},
$$

where: $Z_{o s}$ - normalized coordinate of the etalon.

4. to calculate the upper limits $\mathrm{C}_{\mathrm{o}}$ of the options using:

$$
\begin{gathered}
c_{o}=\bar{c}_{o}+2 S_{0}, \\
\bar{c}_{o}=\frac{1}{w} \sum_{i=1}^{w} c_{i 0},
\end{gathered}
$$




$$
S_{o}=\left[\frac{1}{w} \sum_{i=1}^{w}\left(c_{i o}-\bar{c}_{o}\right)^{2}\right]^{\frac{1}{2}} .
$$

5. to calculate the development score $\left(d_{i}\right)$ of the options using:

$$
d_{i}=1-\frac{c_{i o}}{c_{o}}
$$

An economic interpretation of the development scores or taxonomical indicators is measured from 0 to 1 and the maximum value in this interval indicates the highest level of development.

\subsection{Growth rate analysis of structural effectiveness}

In short, the "structural effectiveness" concept is a system organization displaying an ability to perform in compliance with established target priorities that is reached by following certain proportions in resource and productive characteristics. Structural effectiveness is meant to describe and compare structural features of performance with desirable (normative) ones. To estimate structural effectiveness, we have used a method based on rate of growth estimation. The method is aimed to investigate regional performance during a one-time period based on comparisons of the attribute proportions by comparing the growth rates of attributes:

1. to determine the initial set of attributes: $A^{\text {base }}=\left\{A_{j} \mid j=\overline{1, k}\right\}$.

2. to form the $(N \times K)$ decision matrix $S$, where $s_{i j}$ indicates the performance of $i^{\text {th }}$ region for $i=1, \ldots, N$ according to the $j^{\text {th }}$ attribute;

3. to calculate the basic rates of growth $\left(R_{i j}\right)$ for $i^{\text {th }}$ region and $j^{\text {th }}$ indicator according to the formed negative etalon $E_{i j}{ }^{-}=\min _{i} s_{i j}$ :

$$
R_{i j}=\frac{s_{i j}}{E_{i j}{ }^{-}} .
$$

4. to form the structural normative matrix based on the relationships of growth rates between attributes, for instance:

$$
R_{\text {employed }}>R_{\text {econ.active pop. }}>R_{\text {pop. }} \text { or } R_{\text {indust.innov.enterp. }}>R_{\text {indust.enterp. }}
$$

5. to calculate the difference $\Delta R_{i}^{j, m}$ in growth rates between $j$ and $m$ attributes:

$$
\Delta R_{i}^{j, m}=R_{i j}-R_{i m} .
$$

6. to form the derived set of differences $\Delta R$ : 


$$
\Delta R=\left\{r_{v} \mid v=1 \ldots f\right\},
$$

where: $f$-number of relationships between $j$ and $m$ attributes.

7. to normalize the differences using standard deviation method:

$$
z_{i v}=\frac{\Delta r_{i v}-\Delta \bar{r}_{v}}{S_{v}},
$$

where: $\Delta \bar{r}_{v}$ - average difference of $v$-th relationship;

$$
S_{v} \text { - standard deviation of } \Delta r_{i v} \text { for all } n \text { regions. }
$$

8. to form a matrix of standardized differences:

$$
Z=\left[\begin{array}{l}
z_{11} \ldots z_{1 v} \ldots z_{1 f} \\
\ldots \ldots \ldots \ldots \ldots \\
z_{i 1} \ldots z_{i v} \ldots z_{i f} \\
z_{n 1} \ldots z_{n v} \ldots z_{n f}
\end{array}\right] .
$$

9. to measure structural effectiveness (St.) by way of a summation of standardized differences:

$$
S t_{\cdot i}=\sum_{v=1}^{f} z_{i v} .
$$

Having found the basic rates of growth in relation to the negative etalon within one attribute, the next comparison will be of the growth rates of different attributes. In this way, double comparisons are obtained. Basing on this, we can establish the difference in performance proportions between the evaluated regions. Due to this descriptive nature and normative orientation of the indicator, we can see which features of performance should be enhanced. This method, as the two previous ones, is also able to rank regions.

\subsection{Resonance approach algorithm}

The resonance approach for the determination of lagging regional policy interventions is a non-compensatory approach based on the resonance principle applied to both NUTS 1 and NUTS 2 levels representing the administrative division of European regions. The procedure of the suggested method, which combines decision alternatives into one compromise resonance solution, is provided below:

1. definition of alternatives according to the $\mathrm{E}$ (technical efficiency), $\mathrm{R}$ (resource level) and St. (structural effectiveness) dimensions of competitiveness and according to the two external $G, S$ managerial levels $(\mathrm{G}-$ general index for NUTS 1 regions, $\mathrm{S}-$ specific index in charge of the NUTS 2 level) and one additional intra-level $L$ level used for structural effectiveness; 
1.1 decision matrices $G^{E}$ and $G^{R}$ are $(F \times K)$ matrices in which elements $g_{m j}^{E}$ and $g_{m j}^{R}$ separately indicate the performance of alternative $G_{m}$ (NUTS 1 region) for $m=1, \ldots, F$ according to $\mathrm{E}$ and $\mathrm{R}$ dimensions;

1.2 decision matrices $S^{E}$ and $S^{R}$ are $(N \times K)$ matrices in which element $s_{i j}^{E}$ and $s_{i j}^{R}$ separately indicate the performance of alternative $S_{i}$ (NUTS 2 region) for $i=1, \ldots, N$ according to $\mathrm{E}$ and $\mathrm{R}$ dimensions, when $S=\left\{s_{i}\right\}=\bigcup_{g \in G} g \mid N>F ;$

1.3 decision matrix $L$ constitutes $(N \times K)$ matrices in which element $l_{p j}$ indicates the performance of alternative $L_{i}$ (NUTS 2 region) for $i=1, \ldots, N$ according to the St. (structural effectiveness) dimension;

2. definition of criteria $C_{j}$ based on the aspects of competitiveness measurement, namely human, business and meso-level group (table 5). Alternatives $G_{m}, S_{i}, L_{i}$ are evaluated in terms of decision criteria $C_{j}$ for $j=1, \ldots, K$;

3. transformation of original matrices into ranked ones according to E, R, St. dimensions separately, where the highest rank is assigned to the lowest value (table $6)$;

3.1 transformation of $G$ matrix into the ranked matrix $G^{r}$ in which elements $g_{m j}^{r}$ indicate the performance of $m$-th alternative measured in ranks $\left(r_{m j}^{g}\right)$, so as $\mathrm{g}_{m j}^{r}=\left\langle\begin{array}{c}r_{m j}^{g} \\ \text { in }\end{array}\right.$

3.2 transformation of $S$ matrix into the ranked matrix $S^{r}$ in which elements $s_{i j}^{r}$ indicate the performance of $i$-th alternative measured in ranks $\left(r_{i j}^{\mathrm{s}}\right)$, so that $s_{i j}^{r}=\left\langle r_{i j}^{\mathrm{s}}\right\rangle$;

3.3 transformation of $L$ matrix into the ranked matrix $L^{r}$ in which elements $l_{i j}^{r}$ indicate the performance of $i$-th alternative measured in ranks $\left(r_{i j}^{1}\right)$, so that $l_{i j}^{r}=l\left\langle r_{i j}^{1}\right\rangle$;

4. to define weaknesses for $E, R$, St. dimensions separately for matrices $G^{r}, S^{r}, L^{r}$ (table 9);

4.1 from matrix $G^{r}$ to define the weaknesses $g_{i}$ choosing minimal rank ( $\min _{j} g_{m j}^{r}$ ) for $m$-th alternative with respect to criterion $C_{j}^{g}$; 


\section{REVIEW OF ECONOMIC PERSPECTIVES}

4.2 from matrix $S^{r}$ to define the weaknesses $s_{i}$ choosing minimal rank ( $\min _{j} s_{i j}^{r}$ ) for $i$-th alternative with respect to criterion $C_{j}^{s}$;

4.3 from matrix $L^{r}$ to define the weaknesses $l_{i}$ choosing minimal rank ( $\min _{j} l_{i j}^{r}$ ) for $i$-th alternative with respect to criterion $C_{j}^{l}$;

5. with respect to $\mathrm{E}$ and $\mathrm{R}$ dimensions to define correspondingly possible resonance combinations $M_{i}^{E}$ and $M_{i}^{R}$ for all alternatives as a coincidence of weaknesses criteria $C_{j}$ between $g_{i}, s_{i}, l_{i}$ using match function (M) leading to the different resonance combination (table 9):

$$
M_{i}=M\left(g_{m}, s_{i}, l_{i}\right)=\left\{\begin{array}{l}
C_{j}(G, S, L) \text { if } C_{j}^{g} \equiv C_{j}^{s} \equiv C_{j}^{l} ; \\
C_{j}(G, S) \text { if } C_{j}^{g} \equiv C_{j}^{s} ; \\
C_{j}(G, L) \text { if } C_{j}^{g} \equiv C_{j}^{l} ; \\
C_{j}(S) \text { if } C_{j}^{g} \neq C_{j}^{s} \wedge C_{j}^{g} \neq C_{j}^{l} .
\end{array}\right\} ;
$$

6. to define RI $M_{i}^{*}$ as a $\max _{E, R} M_{i}$ following the resonance preferences $(G, S, L) \succ(G, S) \succ(G, L)$ (table 10$)$;

7. to define ranks $\left(r_{i j}^{M}\right)$ of alternatives $M_{i}^{*}$ in accordance with resonance preferences and finding maximum rank at $G, S$ and $L$ levels $\max _{r(G \rightarrow S \rightarrow L)} \max _{M} M_{i}^{*}$;

8. to determine the homogeneous RI $\left\{M_{i}^{W}\right\}^{\text {homog. }}$ (fig. 6) which have spatial contiguity of the $\mathrm{M}_{\mathrm{i}}$ with the same coincidence criteria $C_{i j}^{M^{*}}$ :

8.1 can be defined visually by mapping;

8.2 can be defined in an analytic way by constructing the $(N \times N)$ matrix $M^{W}$ for which rows are computed as a product of coincidence criterion $C_{i j}^{M^{*}}$ and row $(1 \times n)$ vector $w_{i}=\left(w_{1}, \ldots, w_{n}\right)$ for which values equal 1 (if regional contiguity) or 0 (if discontinuity): 


$$
M^{W}=\left(\begin{array}{c}
C_{1 j}^{M^{*}} \times w_{1} ; \\
\cdots \\
C_{i j}^{M^{*}} \times w_{i} ; \\
\cdots \\
C_{n j}^{M^{*}} \times w_{n} ;
\end{array}\right) \text {, where contiguous } C_{i j}^{M^{*}} \text { to be found; }
$$

9. to define the series of rank-ordered homogeneous RI $\left\{M_{i}^{W}\right\}$ ordered homog.

Six steps of the given algorithm are presented graphically in figure 4. The highest priority is given to the regions having GSL index-combinations with the highest resonance effect.

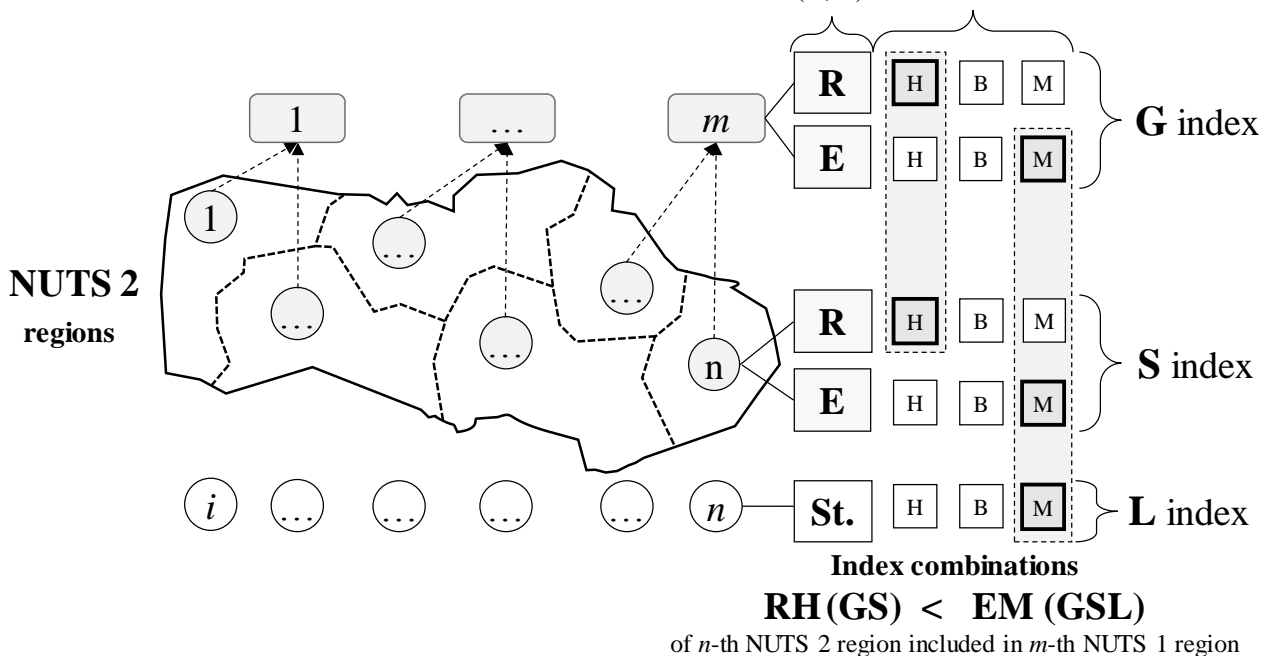

Source: author

\section{Determination of competitiveness regional interventions}

This section leads us to practical results of the described methodologies and allows for decision-making about policy interventions. In the appendix (table 1) we present the Ukrainian NUTS division suggested by Różańska-Putek J., Jappens M., et al. (2009), which we assume to be functional. In this list, Kyiv, the capital city, is presented, as it has a special status and will thus be included in benchmarking. 


\subsection{Preliminary and partial analysis of regional competitiveness}

The list of 27 indicators being used for DEA and growth rate analysis is given in the context of input/output three-group division (appendix, table 2). The logic underpinning such a division is quite flexible. Based on an output-oriented model, we try to increase outputs using no more than the given inputs. For instance, holding such initial inputs for a business group such as employed aged 15-70, staff engaged in R\&D, total expenditure by innovation activity direction and capital investment, we expect such outputs as sold industrial product, innovation products output, gross value added, agricultural output and activity of enterprises operating in services sphere to be increased.

The list of 16 relative input indices (appendix, table 3 ) is used for the other perspective uncovering the extensive dimension through Hellwig's method. This set of indices with the same group structure is intended to give the opposite managerial point of view with a tendency to increase input factors under the condition that the efficiency of their use is already on a relatively high level. The indicators characterizing the resource component have the nature of its relative index; e.g. we use a share of innovatively active industry enterprises among all industry enterprises, but not just the dominator of the index. From this side, an improvement in the business resource level can be achieved with an increase of the level of employment rate, personnel engaged in research and development activities, innovative expenditures and investments per 1 business unit. Both strongly different output or input increasing perspectives are provided to extend and complement the tools of competitiveness management.

Before space reduction, we check the suitability of the samples on each of the groups of competitiveness by using the Kaiser-Meyer-Olkin indicator and Bartlett's test. Table 4 shows that the chosen indicators are suitable (KMO for all groups > 0.6; Sig. for all groups < 0.05) for further space reduction and obtaining the competitiveness factors measured by sub-indicators of competitiveness.

Table 4 KMO and Bartlett's Test

\begin{tabular}{ccccc}
\hline \multicolumn{2}{c}{ Indicator / Groups } & H & B & M \\
\hline Kaiser-Meyer-Olkin Measure of sampl. adeq. & .758 & .707 & .791 \\
& Approx. Chi- & 453.406 & 257.926 & 409.311 \\
Bartlett's Test of & Square & 36 & 36 & 36 \\
Sphericity & df & .000 & .000 & .000 \\
\hline
\end{tabular}

Source: author

To estimate structural effectiveness, normative relationships between the growth rates of different basic indices must be established. Structural effectiveness (the $L$ index) is not considered during the clustering process because it is a kind of combination of both aforementioned dimensions and it will serve later as an additional dimension for the final decision-making process linked to resonance effect identification.

The first preliminary space reduction step is merely the application of the methods described in sections $3.1,3.2$ and 3.3. This leads to the estimation of 9 variables 
representing the composite sub-indicators of $\mathrm{RC}$ based on 3 aspects and 3 dimensions (table 5).

Table 5. Components of the $\mathrm{RC}$ in the light of aspects and dimensions

\begin{tabular}{l|l|c|c|c}
\hline \multicolumn{2}{c|}{ Criteria (variables) } & \multicolumn{3}{c}{ Groups (aspects) } \\
\cline { 3 - 5 } \multicolumn{2}{c|}{} & $\begin{array}{c}\text { Human } \\
\text { capital }(\mathrm{H})\end{array}$ & $\begin{array}{c}\text { Business } \\
(\mathrm{B})\end{array}$ & $\begin{array}{c}\text { Meso-level } \\
(\mathrm{M})\end{array}$ \\
\hline \multirow{3}{*}{ Dimensions } & Resource level (R) & RH & RB & RM \\
\cline { 2 - 5 } & Technical efficiency (E) & EH & EB & EM \\
\cline { 2 - 5 } & Structural effectiveness (St.) & St.H & St.B & St.M \\
\hline
\end{tabular}

Source: author

The second step is a clustering procedure focused on defining the latent variables, namely clusters that have been extracted based only on 6 values $(\mathrm{RH}, \mathrm{EH}, \mathrm{RB}, \mathrm{EB}, \mathrm{RM}$, EM). Having used Ward's Method (minimum variance), the regions are divided into 3 clusters: regions with the highest level of development - "engines" (I cluster); "outsiders," or lagging regions - "brakes" of a country's economy (III cluster); "middle link" - without prominent advantages and disadvantages (II cluster) (table 6). Results of the clustering show that in 2013, Ukraine did not have many salient regions with the best characteristics. In particular, there are only 3 (11,5\%) driving "engines": Kyiv city, Donecky and Dnipropetrovsky. Thus, the lion's share (53\%), including 14 "lagging" regions, is considered to be entitled as pertains to policy making as they create negative multiplicative effects in regional performance and inhibit sustainable development of the country. This means that they are in need of regional interventions for future perspective transformations leading them out from the position of outsiders. Subsequently, more than a half of the regions need to undergo an essential developing regulative intervention. The remaining $34 \%$ (9 regions) is referred to as the $2^{\text {nd }}$ middle cluster, where regions do not have an urgent need to be recipients of interventions.

\subsection{Benchmarking of regional competitiveness, sensitivity analysis of composite indicators}

This section focuses on benchmarking NUTS 2 regions based on the composite indicators. The aggregating function could take on various forms leading to the compensatory effect, such as additive or multiplicative functions. In this research, the compensatory effect is demonstrated through an additive function providing a relatively high degree of variability of ranks. To compute $\mathrm{CI}$, we aggregate $\mathrm{RH}, \mathrm{EH}, \mathrm{RB}, \mathrm{EB}$, RM, EM. Due to the limited scope of this paper, the weights of sub-indicators are considered the only factor of uncertainty. Therefore, to examine the variability of ranks, we conduct a simple simulation procedure, where the parity of weights will serve as the starting point of sensitivity analysis. All 6 sub-indicators will be transformed into a $[0 ; 1]$ variability range using the step $\frac{1}{k \times p}$ (where $\mathrm{p}$ is 10 ) turning $k-1$ sub-indicators in equal proportion. Having formed the 61 set of technically admissible weights for each sub-indicator, we obtained $6 \times 61$ sets in total and consequently, the same number of sets of ranks. For every $j$-th NUTS 2 region we found mean rank $\left(\bar{r}_{i}\right)$, standard deviation ( 
$\left.\sigma_{i}\right)$, max rank $\left(r_{i}^{\max }\right)$ and $\min \operatorname{rank}\left(r_{i}^{\min }\right)$. The variability of ranks is analysed using two approaches, namely the max-min and standard deviation approach. Correspondingly, robustness $(\bar{R})$ can be measured in two ways:

$$
\begin{aligned}
\bar{R}^{\max -\min } & =1-\frac{\sum_{i=1}^{n} r_{i}^{\max }-r_{i}^{\min }}{n^{2}} ; \\
\bar{R}^{\sigma} & =1-\frac{\sum_{i=1}^{n} 2 \times \sigma_{i}}{n^{2}} .
\end{aligned}
$$

Having checked the correlation between composite $C I, G D P$ and sub-indicators, we determined the correlation between $R M$ and other indicators to be $<0.5$ and not statistically significant. This means that this sub-indicator is the subject of exclusion. Then we once again formed the 51 set of weights for all 5 remaining sub-indicators, in total we obtained $5 \times 51$ sets of weights and possible sets of ranks. With this number of sub-indicators, the correlation appeared to be relatively strong and significant at the $5 \%$ level (table 8). We can now thus conclude that the way the index is constructed is sound. Due to the exclusion of the $R M$ component, the level of max-min robustness increased from $49.7 \%$ to $62.28 \%$, and the $\sigma$ robustness changed slightly from $80.42 \%$ to $82.61 \%$ (fig. 5 ).

Figure 5. Variability of CI ranks of NUTS 2 regions

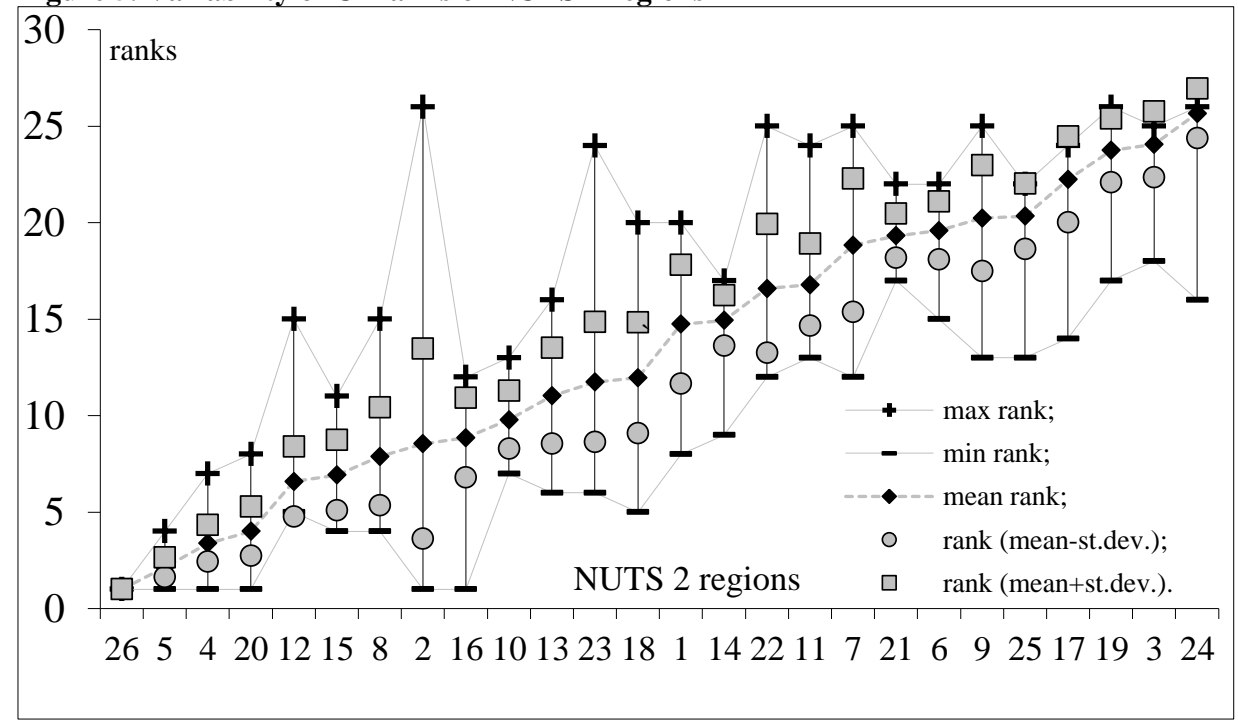

Source: author

Even though we decreased the level of CI variability, on average, there are still 2.26 ranks per 1 region and the presence of the high max-min ranks' variability is at $38 \%$, which represents quite a negative precondition for forming certain regional policy interventions. Thus, a sufficiently high variability level indicates the main limitation and 
drawback of the CI composite. That is why, to avoid the compensatory effect and high sensitivity of the ranks, resonance approach is applied in the following subsection.

\subsection{Application of the resonance approach}

In table 6 (appendix) the ranks of regions are presented in the context of two NUTS levels. The content of this table is the foundation for determining the direction of each region improvement.

According to the resonance approach, the components of competitiveness are already composite indicators and they are not subject to the further total aggregation leading to a single aggregated competitiveness index. Taking this position, we state that the more complex the system we investigate, the more differential the approach to its characteristics should be applied. This means that further during target determination, each component is treated individually without any aggregation. For this purpose, we proposed the concept of dominant resonance index-combination to define the focus of policy interventions. Following the steps listed in subsection 3.4, we arrived at resonance combinations for the NUTS 2 lagging regions from the "weakest" cluster III (table 9).

Table 9. Determination of the dominating combinations for the "weakest" cluster III

\begin{tabular}{|c|c|c|c|c|c|c|c|}
\hline \multirow{3}{*}{ Region } & \multicolumn{6}{|c|}{$\begin{array}{l}\text { Weaknesses in the } 3 \text { dimensions: } \\
\text { (worst rank), B-business, H-human, M-meso-level }\end{array}$} & \multirow{3}{*}{$\begin{array}{l}\text { Dominating } \\
\text { combination }\end{array}$} \\
\hline & \multicolumn{2}{|c|}{ Resource level (R) } & \multicolumn{2}{|c|}{ Efficiency (E) } & \multirow{2}{*}{$\begin{array}{c}\begin{array}{c}\text { Structural } \\
\text { effect. } \\
\text { (St.) }\end{array} \\
\begin{array}{c}\text { Intra level } \\
\text { (L) }\end{array}\end{array}$} & \multirow{2}{*}{$\begin{array}{l}\text { Relations between } \\
\text { possible index } \\
\text { resonance } \\
\text { combinations }\end{array}$} & \\
\hline & $\begin{array}{l}\text { NUTS } 1 \\
(G)\end{array}$ & $\begin{array}{l}\text { NUTS } \\
2(\mathrm{~S})\end{array}$ & $\begin{array}{l}\text { NUTS } 1 \\
\text { (G) }\end{array}$ & $\begin{array}{l}\text { NUTS } 2 \\
\quad(\mathrm{~S})\end{array}$ & & & \\
\hline 1 & (6) B & (14) M & $\begin{array}{l}(11) \\
\mathrm{H}, \mathrm{B}\end{array}$ & (20) B & (10) B & $\mathrm{RB}(\mathrm{GL})<\mathrm{EB}(\mathrm{GSL})$ & EB (GSL) \\
\hline 3 & (10) B & (19) B & (10) B & (25) B & (20) H,B & $\mathrm{RB}(\mathrm{GSL})<\mathrm{EB}(\mathrm{GSL})$ & $\mathrm{EB}(\mathrm{GSL})$ \\
\hline 6 & (9) $\mathrm{H}$ & (22) B & (7) B & (21) B & (24) B,M & $\mathrm{RB}(\mathrm{SL})<\mathrm{EB}(\mathrm{GSL})$ & EB (GSL) \\
\hline 7 & $\begin{array}{l}(10) \\
\mathrm{H}, \mathrm{M}\end{array}$ & (25) M & (11) M & (25) $\mathrm{H}$ & (24) $\mathrm{H}$ & $\mathrm{RM}(\mathrm{GS})$ & $\mathrm{RM}(\mathrm{GS})$ \\
\hline 9 & (9) $\mathrm{M}$ & $(25) \mathrm{B}$ & (8) B & (22) B & (21) M & $\mathrm{EB}(\mathrm{GS})$ & $\mathrm{EB}(\mathrm{GS})$ \\
\hline 11 & (7) B & (20) B & (5) $\mathrm{M}$ & (24) M & (23) $\mathrm{H}$ & $\mathrm{RB}(\mathrm{GS})>\mathrm{EM}(\mathrm{GS})$ & $\mathrm{RB}(\mathrm{GS})$ \\
\hline 14 & $\begin{array}{c}(11) \\
\mathrm{H}, \mathrm{B}, \mathrm{M} \\
\end{array}$ & (11) $\mathrm{H}$ & (5) $\mathrm{H}, \mathrm{B}$ & (17) B & (16) $\mathrm{H}$ & RH (GSL)>EB (GS) & $\mathrm{RH}(\mathrm{GSL})$ \\
\hline 17 & (10) B & (23) B & (10) B & (24) B & $(25) \mathrm{H}$ & $\mathrm{EB}(\mathrm{GS})>\mathrm{RB}(\mathrm{GS})$ & $\mathrm{EB}(\mathrm{GS})$ \\
\hline 18 & (4) $\mathrm{H}$ & (8) $\mathrm{H}$ & (8) M & (20) M & (20) M & RH(GS)<EM(GSL) & EM(GSL) \\
\hline 19 & (9) M & (26) B & (8) B & $(25) \mathrm{M}$ & (26) B & $\mathrm{EB}(\mathrm{GL})$ & $\mathrm{EB}(\mathrm{GL})$ \\
\hline 21 & $\begin{array}{c}(11) \\
\mathrm{H}, \mathrm{B}, \mathrm{M}\end{array}$ & (19) $\mathrm{H}$ & (5) $\mathrm{H}, \mathrm{B}$ & (21) $\mathrm{H}$ & (18) $\mathrm{H}$ & $\mathrm{EH}(\mathrm{GSL})<\mathrm{RH}(\mathrm{GSL})$ & RH(GSL) \\
\hline 22 & (10) B & $(25) \mathrm{H}$ & (10) B & (17) $\mathrm{M}$ & (22) B,M & $\mathrm{RB}(\mathrm{GL})<\mathrm{EB}(\mathrm{GL})$ & $\mathrm{EB}(\mathrm{GL})$ \\
\hline 24 & $\begin{array}{l}\text { (10) H, } \\
\mathrm{M}\end{array}$ & (24) M & (11) $\mathrm{M}$ & $\begin{array}{c}(26) \\
H, B, M\end{array}$ & (26) H,M & $\mathrm{EM}(\mathrm{GSL})>\mathrm{RM}(\mathrm{GSL})$ & $\mathrm{EM}(\mathrm{GSL})$ \\
\hline 25 & (9) $\mathrm{H}$ & (21) $\mathrm{H}$ & (7) $\mathrm{B}$ & (23) $\mathrm{H}$ & (21) B & $\mathrm{RH}(\mathrm{GS})>\mathrm{EB}(\mathrm{GL})$ & RH(GS) \\
\hline
\end{tabular}

Source: author

These regions are the first ones standing in the queue for interventions among all regions being compared. The ranking process for the lagging regions from the $3^{\text {rd }}$ cluster is shown in table 10 . In the case of the EM(GSL) combination of the $24^{\text {th }}$ region, we see the importance of interventions for the meso-level group (M) directed toward the 
improvement of technical efficiency (E) for three levels (G, S, L); the RM(GS) combination shows the necessity of interventions of two levels for $\mathrm{M}$ focused on increasing the resource level $(\mathrm{R})$.

The data is sorted according to the preferences (importance) of combinations (GSL $>$ GS $>$ GL). For instance, for region 24 with a triple match of G, S, L indices, the first step is to define the rank of region on the $\mathrm{G}$ index. The rank of this region is $11^{\text {th }}$ according to EM. A complication arises in that, in the GSL group, a similar rank is observed in regions ranked $1^{\text {st }}, 14^{\text {th }}, 21^{\text {st }}$ and $24^{\text {th }}$. This causes a transition to the succeeding $\mathrm{S}$ index level, where we have to compare new ranks of the mentioned peer regions. All new received ranks are different, which implies it is not necessary to proceed to the L index level. After being ranked, the worst regions have the highest priority for intervention. Region 24 has the worst rank (26) on the $\mathrm{S}$ index level and is thereby ranked $1^{\text {st }}$ for RI.

Table 10. Ranking regions from cluster III based on the urgency of interventions

\begin{tabular}{|c|c|c|c|c|c|}
\hline $\begin{array}{c}\text { Preferences } \\
\text { of } \\
\text { combinations' } \\
\text { (1- the most } \\
\text { urgent) }\end{array}$ & Region & $\begin{array}{l}\text { Resonance } \\
\text { combination }\end{array}$ & $\begin{array}{c}\text { Rank of G } \\
\text { index }\end{array}$ & $\begin{array}{l}\text { Rank of S } \\
\text { index }\end{array}$ & $\begin{array}{c}\text { Final } \\
\text { intervention } \\
\text { ranking }\end{array}$ \\
\hline 1 & 24 & $\mathrm{EM}(\mathrm{GSL})$ & 11 & $\rightarrow 26$ & $\longrightarrow 1$ \\
\hline 1 & 1 & EB(GSL) & $11-$ & $\longrightarrow 20$ & $\longrightarrow 2$ \\
\hline 1 & 21 & RH(GSL) & $11-$ & $\longrightarrow 19$ & $\longrightarrow 3$ \\
\hline 1 & 14 & RH (GSL) & $11-$ & $\longrightarrow 11$ & $\longrightarrow 4$ \\
\hline 1 & 3 & $\mathrm{~EB}(\mathrm{GSL})$ & $10-$ & & $\longrightarrow 5$ \\
\hline 1 & 18 & EM(GSL) & $8-$ & & $\longrightarrow 6$ \\
\hline 1 & 6 & EB (GSL) & 7 & 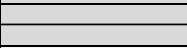 & $\longrightarrow 7$ \\
\hline 2 & 7 & $\mathrm{RM}(\mathrm{GS})$ & $10-$ & $\longrightarrow 25$ & $\longrightarrow 8$ \\
\hline 2 & 17 & $\mathrm{~EB}(\mathrm{GS})$ & $10-$ & $\rightarrow 24$ & $\longrightarrow 9$ \\
\hline 2 & 25 & RH (GS) & $9-$ & & $\longrightarrow 10$ \\
\hline 2 & 9 & $\mathrm{~EB}(\mathrm{GS})$ & 8 & & $\longrightarrow 11$ \\
\hline 2 & 11 & $\mathrm{RB}(\mathrm{GS})$ & $7-$ & & $\longrightarrow 12$ \\
\hline 3 & 22 & $\mathrm{~EB}(\mathrm{GL})$ & $10-$ & & $\longrightarrow 13$ \\
\hline 3 & 19 & $\mathrm{~EB}(\mathrm{GL})$ & $8-$ & & $\longrightarrow 14$ \\
\hline
\end{tabular}

Source: author

Next, we begin testing the hypotheses outlined in section 2.2. The first that should be tested is whether there is correlation between RI and the level of CI or its components using data for lagging regions. As we see from table 11, corr (RI, CI) and corr (RI, GDP) are extremely low and the alternative hypothesis $\mathrm{H}_{1}(\mathrm{~A})$ cannot be accepted. This means that the algorithm based on resonance weaknesses in the frame of lagging regions does not correspond with the economic or competitiveness level. However, we can accept hypothesis $\mathrm{H}_{\text {alt. }}$ (B) and assume that there is sufficient correlation between $\mathrm{RI}$ and $\mathrm{RB}(0.723)$. 
Table 11. Correlation between the RI, CI and its components

\begin{tabular}{r|l|c|c|r|r|r|r|r|r}
\hline \multicolumn{2}{c|}{ Variables } & \multicolumn{1}{c|}{ RH } & \multicolumn{1}{c|}{ EH } & \multicolumn{1}{c|}{ RB } & \multicolumn{1}{c|}{ EB } & RM & EM & CI & GDP \\
\hline \multirow{2}{*}{ RI rank } & Spearm. rho & .160 & -.279 & $.723 * *$ & -.176 & .064 & .134 & .073 & -.042 \\
\cline { 2 - 11 } & Sig. (2-tailed) & .584 & .333 & .003 & .547 & .829 & .648 & .805 & .887 \\
\hline
\end{tabular}

**. Correlation is significant at the 0.01 level (2-tailed).

Source: author

Next, C and D hypothesis types are tested visually with a map (fig. 6). All NUTS 1 regions on the map are marked with their own pattern and three different colours of patterns signify the level of general competitiveness described by cluster number (the best, lightest is cluster I, the worst, darkest is cluster III). Results from the map illustrate the aggregated parts of competitiveness and localization of RI stirring up synergetic activities in the region. For instance, we can observe the group of regions in the West with the lowest competitiveness. The type of economic activities these regions concentrate on can explain their low competitiveness. In particular, these are western regions mostly focused on agricultural activity and southern regions focused on fishing and shipbuilding sectors. Both groups of regions suffer from a low level of life quality caused by the character of their economic activities.

Figure 6. Clustering of Ukrainian regions in 2013

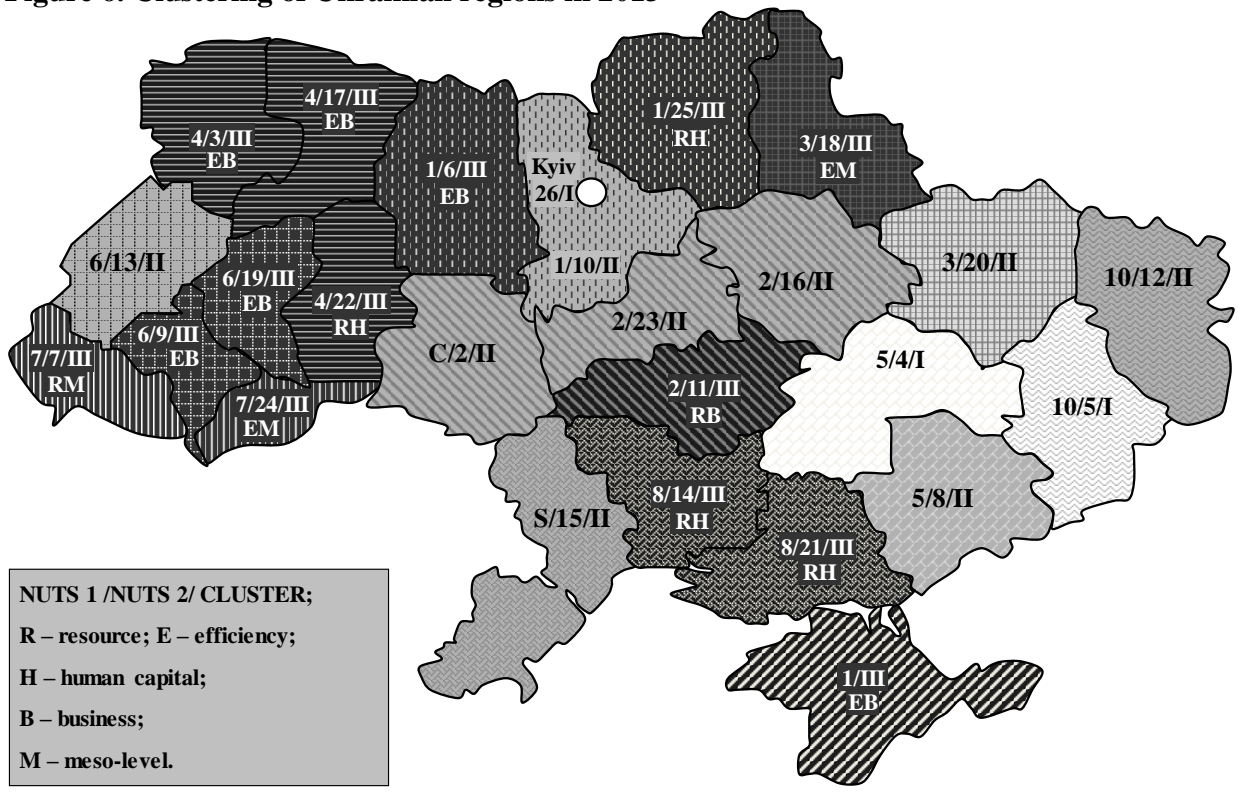

Source: author

The next step is to test hypothesis $\mathrm{C}$ and find neighbouring regions with a coincidence of targets on both NUTS 1 and 2 levels. For western regions, the set of business efficiency (EB) interventions turned out to be a necessity for the $3^{\text {rd }}, 6^{\text {th }}, 9^{\text {th }}, 17^{\text {th }}, 19^{\text {th }}$, and $22^{\text {nd }}$ region. Relying on such an agglomeration of lagging regions with contiguous homogeneous regions, we can reject $\mathrm{H}_{0}(\mathrm{C})$ and state that there is the area homogeneous with corresponding RI targeted at neighbouring NUTS 2 regions. In this case, it would 
be advisable to utilise any policy instruments directed at business efficiency development within regions infrastructure investments, innovative programs, subsidies to business, etc. Concerning $\mathrm{H}_{0}$ (D), we are unable to reject it, as the mentioned regions do not follow each other in a series (one by one) in the final intervention order (table $10)$.

Such synchronized interventions will trigger the resonance effect, initiating synergetic activities. What is more, it will provide for the rise of both country economic growth and regional equity. Attention should be paid to the absence of the strong region from cluster I - otherwise, all interventions could increase overflow of businesses from the poor regions in cluster III to the closest cluster I "reach" region, only creating greater disparities between them.

\section{Conclusions}

The regional interventions based on competitiveness can be more objective and lead to a more effective decrease in regional inequality. To provide such a result, the approach to competitiveness interventions should properly consider the systemic and specific features of competitiveness, such as its "magnetic" essence, dimensions and resonance effect of weaknesses coinciding from both hierarchical and spatial aspects.

The attractiveness of regions has been regarded as a key property of competitiveness, since attractive regions are capable of boosting the concentration of business activities and, as a result, providing sufficient labour conditions. The higher the $\mathrm{RC}$, the more factors of growth it possesses and as a consequence, the better conditions it has for leaving. Thus, according to the concept of area attractiveness, competitiveness is measured in the context of three groups of "consumers" - human capital, business and mixed meso-level groups.

Having analysed the structure of competitiveness, two of its dimensions were chosen to be explored using Hellwig's indicator and DEA methods. Brought together, these methods go in line with methodological pluralism and complement competitiveness measurement practice by introducing extensive and intensive aspects revealed by resource (Hellwig's indicator) and technical efficiency (DEA) components correspondingly.

Policy interventions for lagging regions from the weakest cluster are based on the coincidence between weaknesses of NUTS 1 and included NUTS 2 regions, which in fact represents hierarchical resonance of weaknesses. Speaking in a systemic way, the element (NUTS 2 region) can influence the system the most effectively if the former's changes are in coincidence with desirable changes for the latter.

Concerning practical results, we have found no correlation between regional RI and RC or economic development levels. It means that neither of these commonly used aggregate characteristics correspond to the interventions based on the resonance approach. However, sufficient correlation was found with resource level of business group (RB), meaning that low level of employment rate, personnel engaged in research and development activities, innovative expenditures and investments appeared to be the most defining factor in the necessity of RI. Meanwhile, the set of homogeneous RI based on hierarchical and spatial coincidence was determined in western Ukraine and 
includes six NUTS 2 regions $\left(3^{\text {rd }}, 6^{\text {th }}, 9^{\text {th }}, 17^{\text {th }}, 19^{\text {th }}, 22^{\text {nd }}\right)$. All these regions with a dominant agricultural sector of the economy need interventions focused on increasing business attractiveness through the improvement of their efficiency conditions leading to both regional economic growth and equity.

As regards to further developments, it should be stated that the resonance approach could be applied on three managerial levels, such as NUTS 2, NUTS 1 and country level, bringing an even higher effect in the light of bigger scale resonance target synchronization. It should be mentioned that the main drawback of this research is the assumption of equality of the NUTS 1 division and functional groups consisting of the most spatially correlated NUTS 2 regions. That is the way future research should implement the step of identifying true functional regions.

Funding: This article has been funded by the INFINITY project in the framework of EU Erasmus Mundus Action 2.

Disclosure statement: No potential conflict of interest was reported by the author.

\section{References}

Ahner D (2009). What do you really know about European Cohesion Policy? Notre Europe, Brussels. www.notre-europe.eu. (Accessed 20 February 2013).

Annoni P., Dijsktra L. (2013). EU Regional competitiveness Index RCI 2013, European Commission, Brussels.

Annoni P., Dijsktra L., Kozovska K. (2011). A new Regional competitiveness Index: Theory, Methods and Findings. European Commission Working Papers, n. 02/2011.

Annoni P., Kozovska K. (2010). EU Regional competitiveness Index RCI 2010. European Commission, Brussels.

Aranguren, M., Susana F., et al. (2010). Benchmarking Regional Competitiveness in the European Cluster Observatory. European Commission.

Camagni R. Capello R., (2014). Rationale and Design of EU Cohesion Policies in a Period of Crisis with special reference to CEECs. GRINCOH Working Paper Series, Policy Paper n. 1.

Camagni, R. (2011). Policy options for the Latin Arc. In Camagni, R., and Capello, R. (eds), Spatial scenarios in a global perspective: Europe and the Latin Arc Countries. Edward Elgar, Cheltenham (UK), pp. 175-185.

Charles, V., Zegarra, L.F. (2014). Measuring regional competitiveness through Data Envelopment Analysis: A Peruvian case. Expert Systems with Applications, vol.41, is.11, pp. 5371-5381. DOI: $\underline{10.1016 / j . e s w a .2014 .03 .003 ~}$

Charnes A., Cooper, W. W. Rhodes, E. (1978). Measuring the efficiency of decision making units. European Journal of Operational Research, Vol. 2, No. 4, pp. 429-444. DOI: $\underline{10.1016 / 0377-2217(78) 90138-8}$ 
Cooke P. (2007). To construct regional advantage from innovation systems first build policy platforms. European Planning Studies 15, pp. 179-194. DOI: $\underline{10.1080 / 09654310601078671}$

Сооке, P. (2004). Competitiveness as cohesion: Social capital and the knowledge economy. Y: Boddy, M. \& Parkinson, M. City Matters: Competitiveness, Cohesion and Urban Governance, 153 - 170.

Department of Trade and Industry (2002). A Modern Regional Policy for the United Kingdom. DTI, London.

European Commission. (2011). European Competitiveness Report. Brussel.

Fernandez, E., Navarro, J., et al (2013). Core: A decision support system for regional competitiveness analysis based on multi-criteria sorting. Decision support systems 54 (3), pp. 1417-1426. DOI: 10.1016/j.dss.2012.12.009

Flood, R., Jackson, M. (1991). Critical Systems Thinking: Directed Readings. Wiley, New York: Wiley. 347 p.

Flood, R., Romm, N. (1996). Critical Systems Thinking: Current Research and Practice. Plenum Press, New York, 301 p.

Florida, R. (2002). The Rise of the Creative Class - and how it's transforming work, leisure, community, \& everyday life. The Perseus Books Group, New York.

Gábor B., and Ottaviano G. (2015). Micro-founded measurement of regional competitiveness in Europe. Mimeo, CERS-HAS

Harmaakorpi V. (2006). Regional Development Platform Method (RDPM) as a Tool for Regional Innovation Policy. European Planning Studies 14, p.1085-1114.

Harman, H.H. (1976). Modern factor analysis. The University of Chicago Press, Chicago. $-423 \mathrm{p}$.

Hellwig, Z. (1968). "Usage of taxonomic methods for the typological divisions countries", Stat Overview, Vol. 15, No. 4, pp. 307-327.

Hollanders, H., Tarantola, S. and Loschky, A. (2009). Regional Innovation Scoreboard 2009: Methodology Report.

Huggins, R. (2003). Creating a UK Competitiveness Index: Regional and Local Benchmarking. Regional Studies, Vol. 37, pp. 89-96. DOI: 10.1080/0034340022000033420

Huggins, R.; Davies, W. (2006). European Competitiveness Index 2006-07. United Kingdom: Robert Huggins Associates Ltd. 39 p. ISBN 1-902829-03-4.

Hugins, R. and Thompson, P. (2010). UK Competitiveness INDEX 2010. Cardiff: Centre for International Competitiveness.

Huovari, J., Kangasharju, A. and Alanen, A. (2001). Constructing an Index for Regional Competitiveness. Helsinki: Peelervo Economic Research Institute - Working paper No 44. 
Jackson, M. (1991). Systems methodology for the management sciences. New York: Plenum Press, 398 p.

Kiszová, Z. \& Nevima, J. (2012). Usage of analytic hierarchy process for evaluating of regional competitiveness in case of the Czech Republic. Proceedings of the 30th international conference MME, pp. 402-4071.

Kuznets, S. S. (1955). Economic growth and income inequality. American Economic Review, 45, pp. 1-28.

Luhmann, N. (2002). Introduction to Systems Theory. Polity press. Cambridge: 65 Bridge Street. ISBN 074-5-645-720, 978-0-745-645-728.

Martin, P. (1999). Are European regional policies delivering? EIB Papers, 4, pp. 10-23.

Martin, P. and G. I. P. Ottaviano (2001). Growth and agglomeration. International Economic Review, 42, pp. 947-968. DOI: 10.1111/1468-2354.00141

Melecký L., Staníčková M. (2011). The Competitiveness of Visegrad Four NUTS 2 Regions and its Evaluation by DEA Method Application. Proc. 29th Inter. Conf. on Mathematical Methods in Economics, p. 474-479.

Meyer, Dietmar - Lackenbauer, Jörg. (2005). „EU Cohesion Policy and the Equity Efficiency Trade-Off: Adding Dynamics to Martin's Model”. Andrássy Working Paper Series No. XIII.

Midelfart, K. H. (2004). Regional policy design: An analysis of relocation, efficiency and equity. CEPR Discussion Paper No. 4321, Centre for Economic Policy Research (CEPR), London.

Midgley G. (2014). Systemic Intervention. Research Memorandum 95, November 2014. Centre for Systems Studies, Hull University Business School. ISBN 978-1906422-32-5.

Mingers, J., Gill, A. (1997). Multimethodology: The Theory and Practice of Combining Management Science Methodologies. Wiley, Chichester, 442 p.

Myrdal, G. (1957). Economic Theory and under-developed regions. London: Duckworth

Nevima, J., and Ramík, J. (2009). Application of multicriteria decision making for evaluation of regional competitiveness. Proceedings of the 27 th international conference Mathematical methods in economics, pp.239-244.

OECD-JRC. (2008). Handbook on Constructing Composite Indicators. Methodology and User guide. Paris: Paris: OECD

Oliva, M., Miguel , M. (2005). Objective Competitiveness Ranking amongst EU Regions (Objective Method for Quantifying Regional Competitiveness - a case study applied to EU15 Regions). 45th Congress of the European Regional Science Association.

Perroux, F. (1955). Note sur la notion de "pôle de croissance”. Economie appliquée, 12, pp. 307-320. 
Pessoa, A. (2013). Competitiveness, clusters and policy at the regional level: rhetoric vs. practice in designing policy for depressed regions. Regional Science Inquiry Journal, Vol. V, (1), 2013, pp. 101-116.

Pluta W. (1977). Multidimensional Comparative Analysis in economic research. National Economic Publishing House, Warsaw.

Porter, M., \& Ketels, C. (2003). UK Competitiveness: Moving to the Next Stage. DTI Economics Paper.

Puga, D. (2002). European regional policies in light of recent location theories. Journal of Economic Geography, 2, pp. 373-40. DOI: 10.1093/jeg/2.4.373

Poot, J. (2000). Reflections on Local and Economy- Wide Effects of Territorial Competition. In: BATEY, FRIEDRICH, P.: Regional Competition, Springer.

Ramík, J., and Hančlová, J. (2012). Multicriteria methods for evaluating competitiveness of regions in V4 countries. Multiple Criteria Decision Making 12. Katowice: The Karol Adamiecki University of Economics.

Różańska-Putek J., Jappens M., Willaert D. \& Van Bavel J. (2009). Recoding the Regions of the European Social Survey into the NUTS 1 Regional Classification. Illustration: regional indicators of intergenerational solidarity. Interface Demography, Vrije Universiteit Brussel, Pleinlaan 2, B-1050 Brussel, Belgium.

Schaffer, A.; Simar, L.; Rauland, J. (2011). "Decomposing Regional Efficiency," Journal of Regional Science, Vol. 51, No 5, 2011, p. 931-947. DOI: 10.1111/j.14679787.2011.00731.x

Snieška, V. and Bruneckienè, J. (2009). Measurement of Lithuanian Regions by Regional Competitiveness Index. Engineering Economics, 1(61), p. 45-57.

Storper, M. (1997). The regional world: Territorial development in a global economy. New York, NY: The Guilford Press.

Tetsuya, S., Matsumoto, T. (2010). "Policies to Enhance the Physical Urban Environment for Competitiveness: A New Partnership between Public and Private Sectors", OECD Regional Development Working Papers, 2010/1, OECD Publishing, (C) OECD.

UNDP (2008). Regional Competitiveness Index Croatia 2007. Zagreb: United Nations Development Programme. 


\section{Appendix}

Table 1. The structure of Ukrainian regions

\begin{tabular}{|c|c|c|c|}
\hline NUTS 1 region & NUTS 2 regions (oblast) & $\begin{array}{l}\text { NUTS } 1 \\
\text { region }\end{array}$ & $\begin{array}{l}\text { NUTS } 2 \text { regions } \\
\text { (oblast) }\end{array}$ \\
\hline 1. NORTH (N) & $\begin{array}{l}6 \text { (Zhytomyrska), } \\
10 \text { (Kyivska), } \\
25 \text { (Chernigivska) }\end{array}$ & 6. WEST (W) & $\begin{array}{l}\text { (Ivano-Frankivska) } \\
13 \text { (Lvivska) } \\
19 \text { (Ternopilska) } \\
\end{array}$ \\
\hline \multirow[b]{2}{*}{ 2. CENTER (C) } & \multirow{2}{*}{$\begin{array}{l}2 \text { (Vynnytska) } \\
11 \text { (Kirovogradska) } \\
16 \text { (Poltavska) } \\
23 \text { (Cherkasska) }\end{array}$} & $\begin{array}{l}\text { 7. SOUTH - } \\
\text { WEST (SW) }\end{array}$ & $\begin{array}{l}7 \text { (Zakarpatska) } \\
24 \text { (Chernovytska) }\end{array}$ \\
\hline & & 8. SOUTH (S) & $\begin{array}{l}14 \text { (Mykolaivska) } \\
15 \text { (Odesska) } \\
21 \text { (Khersonska) }\end{array}$ \\
\hline 3. NORTH-EAST (NE) & $\begin{array}{l}18 \text { (Sumska) } \\
20 \text { (Kharkivska) }\end{array}$ & 9. CRIMEA & 1 (Respublika Krym) \\
\hline 4. NORTH-WEST (NW) & $\begin{array}{l}3 \text { (Volynska) } \\
17 \text { (Rivenska) } \\
22 \text { (Khmelnitska) }\end{array}$ & 10. EAST (E) & $\begin{array}{l}5 \text { (Donecka) } \\
12 \text { (Luganska) }\end{array}$ \\
\hline 5. SOUTH-EAST (SE) & $\begin{array}{l}4 \text { (Dnipropetrovska) } \\
8 \text { (Zaporizska) }\end{array}$ & $\begin{array}{l}\text { 11. KYIV } \\
\text { CITY }\end{array}$ & 26 (Kyiv city) \\
\hline
\end{tabular}

Source: administrative territorial division on 2013 year; Różańska-Putek J. et al. (2009) 
Table 2. Division of factors for DEA and rates of growth analysis

\begin{tabular}{|c|c|}
\hline Name & Measure \\
\hline \multicolumn{2}{|l|}{1.1 Inputs of human capital group $(\mathrm{H})$} \\
\hline $\begin{array}{l}\text { Public assistances and another received } \\
\text { current transfers }\end{array}$ & money units \\
\hline Population & persons \\
\hline Staff training and developing & persons \\
\hline Demand for labour force & persons \\
\hline \multicolumn{2}{|l|}{1.2 Outputs of human capital group $(\mathrm{H})$} \\
\hline Total wages of population & money units \\
\hline Job placement of registered unemployed & persons \\
\hline Population income & money units \\
\hline Housing stock & square meters \\
\hline Final households consumption & money units \\
\hline \multicolumn{2}{|l|}{2.1 Inputs of business group (B) } \\
\hline Employed aged $15-70$ & persons \\
\hline Staff engaged in $R \& D$ & persons \\
\hline $\begin{array}{l}\text { Total expenditure by innovation activity } \\
\text { direction }\end{array}$ & units of money \\
\hline Capital investment & units of money \\
\hline \multicolumn{2}{|l|}{ 2.1 Outputs of business group (B) } \\
\hline Sold industrial products (operations, services) & units \\
\hline Innovation products output & money units \\
\hline Gross value added & money units \\
\hline Agricultural output & money units \\
\hline $\begin{array}{l}\text { Activity of enterprises operating in services } \\
\text { sphere }\end{array}$ & money units \\
\hline \multicolumn{2}{|l|}{ 3.1 Inputs of meso-level group (M) } \\
\hline Economically active population & persons \\
\hline The number of used advanced technologies & units \\
\hline $\begin{array}{l}\text { Number of innovation active enterprises in } \\
\text { industry }\end{array}$ & units \\
\hline Number of Business register entities & units \\
\hline \multicolumn{2}{|l|}{3.2 Outputs of meso-level group (M) } \\
\hline Total exports of goods & money units \\
\hline Total exports of services & money units \\
\hline Direct foreign investment (equity capital) & money units \\
\hline Taxes excluding subsidies & money units \\
\hline Final consumers expenditure & money units \\
\hline
\end{tabular}


Table 3. Relative indices describing the level of resource component

\begin{tabular}{|c|c|}
\hline Name & Measure \\
\hline \multicolumn{2}{|l|}{ 1. Human capital group $(\mathrm{H})$} \\
\hline Population density & $\begin{array}{l}\text { persons / } \\
\text { square kilometre }\end{array}$ \\
\hline Social current transfers per 1 person & money units / person \\
\hline Share of trained staff in economically active population & $\%$ \\
\hline Labour demand for 1 job vacancy & persons \\
\hline \multicolumn{2}{|l|}{ 2. Business group $(\mathrm{B})$} \\
\hline Employment rate & $\%$ \\
\hline $\begin{array}{l}\text { Personnel engaged in research and development activities per } \\
\text { business unit }\end{array}$ & persons / enterprise \\
\hline Innovative expenditures per 1 business unit & $\begin{array}{l}\text { money units / business } \\
\text { unit }\end{array}$ \\
\hline Investments per 1 business unit & $\begin{array}{l}\text { money units / business } \\
\text { unit }\end{array}$ \\
\hline \multicolumn{2}{|l|}{ 3. Meso-level group (M) } \\
\hline Number of business entities per persons & units / person \\
\hline $\begin{array}{l}\text { Share of innovation active enterprises in industry from business } \\
\text { entities }\end{array}$ & $\%$ \\
\hline $\begin{array}{l}\text { The number of advanced technologies used per enterprise } \\
\text { utilizing innovative technologies }\end{array}$ & units \\
\hline Share of economically active population in whole population & $\%$ \\
\hline
\end{tabular}

Source: author 
Table 6. Clusters and ranks of the regions in the light of two NUTS levels, three aspects and three dimensions

\begin{tabular}{|c|c|c|c|c|c|c|c|c|c|c|c|c|c|c|c|c|}
\hline \multirow{3}{*}{ 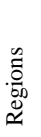 } & \multirow{3}{*}{ 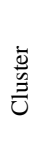 } & \multicolumn{6}{|c|}{$G$ index (NUTS 1) } & \multicolumn{9}{|c|}{$S, L$ indices (NUTS 2) } \\
\hline & & \multicolumn{2}{|c|}{$H$} & \multicolumn{2}{|c|}{$B$} & \multicolumn{2}{|c|}{$M$} & \multicolumn{3}{|c|}{$H$} & \multicolumn{3}{|c|}{$B$} & \multicolumn{3}{|c|}{$M$} \\
\hline & & $r_{m}^{R H}$ & $r_{m}^{E H}$ & $r_{m}^{R B}$ & $r_{m}^{E B}$ & $r_{m}^{R M}$ & $r_{m}^{E M}$ & $r_{i}^{R H}$ & $r_{i}^{E H}$ & $r_{i}^{L H}$ & $r_{i}^{R B}$ & $r_{i}^{E B}$ & $r_{i}^{L B}$ & $r_{i}^{R M}$ & $r_{i}^{E M}$ & $r_{i}^{L M}$ \\
\hline 4 & I & 3 & 8 & 3 & 1 & 2 & 3 & 3 & 7 & 2 & 3 & 1 & 3 & 9 & 3 & 2 \\
\hline 5 & I & 2 & 1 & 4 & 1 & 7 & 1 & 2 & 1 & 4 & 4 & 1 & 4 & 17 & 1 & 4 \\
\hline 26 & I & 1 & 1 & 1 & 1 & 3 & 1 & 1 & 1 & 1 & 1 & 1 & 1 & 4 & 1 & 1 \\
\hline 2 & II & 6 & 1 & 7 & 1 & 6 & 5 & 26 & 1 & 14 & 14 & 1 & 16 & 10 & 11 & 16 \\
\hline 8 & II & 3 & 8 & 3 & 1 & 2 & 3 & 4 & 5 & 8 & 6 & 15 & 9 & 2 & 10 & 6 \\
\hline 10 & II & 9 & 6 & 8 & 7 & 8 & 6 & 12 & 13 & 6 & 10 & 7 & 12 & 22 & 7 & 10 \\
\hline 12 & II & 2 & 1 & 4 & 1 & 7 & 1 & 6 & 9 & 9 & 15 & 6 & 5 & 18 & 8 & 13 \\
\hline 13 & II & 8 & 4 & 5 & 8 & 9 & 7 & 15 & 8 & 15 & 7 & 16 & 15 & 11 & 6 & 9 \\
\hline 15 & II & 11 & 5 & 11 & 5 & 11 & 4 & 10 & 10 & 5 & 11 & 9 & 8 & 26 & 4 & 5 \\
\hline 16 & II & 6 & 1 & 7 & 1 & 6 & 5 & 5 & 11 & 10 & 12 & 1 & 6 & 13 & 12 & 12 \\
\hline 20 & II & 4 & 7 & 2 & 6 & 1 & 8 & 7 & 1 & 3 & 2 & 8 & 2 & 3 & 5 & 3 \\
\hline 23 & II & 6 & 1 & 7 & 1 & 6 & 5 & 24 & 6 & 12 & 18 & 10 & 18 & 21 & 14 & 23 \\
\hline 1 & III & 5 & 11 & 6 & 11 & 4 & 10 & 9 & 19 & 7 & 8 & 20 & 10 & 14 & 9 & 8 \\
\hline 3 & III & 7 & 9 & 10 & 10 & 5 & 9 & 18 & 24 & 20 & 19 & 25 & 20 & 16 & 21 & 15 \\
\hline 6 & III & 9 & 6 & 8 & 7 & 8 & 6 & 20 & 16 & 11 & 22 & 21 & 24 & 20 & 15 & 24 \\
\hline 7 & III & 10 & 10 & 9 & 9 & 10 & 11 & 23 & 25 & 24 & 21 & 12 & 13 & 25 & 23 & 11 \\
\hline 9 & III & 8 & 4 & 5 & 8 & 9 & 7 & 16 & 18 & 17 & 25 & 22 & 14 & 23 & 13 & 21 \\
\hline 11 & III & 6 & 1 & 7 & 1 & 6 & 5 & 13 & 15 & 23 & 20 & 13 & 19 & 5 & 24 & 19 \\
\hline 14 & III & 11 & 5 & 11 & 5 & 11 & 4 & 11 & 14 & 16 & 9 & 17 & 11 & 1 & 16 & 7 \\
\hline 17 & III & 7 & 9 & 10 & 10 & 5 & 9 & 14 & 20 & 25 & 23 & 24 & 25 & 12 & 22 & 14 \\
\hline 18 & III & 4 & 7 & 2 & 6 & 1 & 8 & 8 & 17 & 19 & 5 & 11 & 7 & 7 & 20 & 20 \\
\hline 19 & III & 8 & 4 & 5 & 8 & 9 & 7 & 17 & 22 & 22 & 26 & 23 & 26 & 19 & 25 & 25 \\
\hline 21 & III & 11 & 5 & 11 & 5 & 11 & 4 & 19 & 21 & 18 & 17 & 18 & 17 & 6 & 19 & 17 \\
\hline 22 & III & 7 & 9 & 10 & 10 & 5 & 9 & 25 & 12 & 21 & 24 & 14 & 22 & 15 & 17 & 22 \\
\hline 24 & III & 10 & 10 & 9 & 9 & 10 & 11 & 22 & 26 & 26 & 16 & 26 & 23 & 24 & 26 & 26 \\
\hline 25 & III & 9 & 6 & 8 & 7 & 8 & 6 & 21 & 23 & 13 & 13 & 19 & 21 & 8 & 18 & 18 \\
\hline
\end{tabular}

Source: author 
Table 7. Correlation between GDP, CI and sub-indicators for 26 NUTS 2 regions

\begin{tabular}{c|l|c|c|c|c|c|c|c}
\hline \multicolumn{2}{c|}{ Indicators } & $\mathrm{RH}$ & $\mathrm{EH}$ & $\mathrm{RB}$ & $\mathrm{EB}$ & $\mathrm{EM}$ & $\mathrm{CI}$ & $\mathrm{GDP}$ \\
\hline \multirow{2}{*}{$\mathrm{RH}$} & $\begin{array}{l}\text { Pearson } \\
\text { Correlation }\end{array}$ & 1 &, $482^{*}$ &, $731^{* *}$ &, $460^{*}$ &, $783^{* *}$ &, $698^{* *}$ &, $810^{* *}$ \\
\cline { 2 - 9 } & Sig. & & 0,013 & 0 & 0,018 & 0 & 0 & 0 \\
\hline \multirow{2}{*}{$\mathrm{EH}$} & $\begin{array}{l}\text { Pearson } \\
\text { Correlation }\end{array}$ &, $482^{*}$ & 1 &, $627^{* *}$ &, $738^{* *}$ &, $695^{* *}$ &, $890^{* *}$ &, $842^{* *}$ \\
\cline { 2 - 9 } & Sig. & 0,013 & & 0,001 & 0 & 0 & 0 & 0 \\
\hline \multirow{2}{*}{$\mathrm{RB}$} & $\begin{array}{l}\text { Pearson } \\
\text { Correlation }\end{array}$ &, $731^{* *}$ &, $627^{* *}$ & 1 &, $528^{* *}$ &, $745^{* *}$ &, $748^{* *}$ &, $871^{* *}$ \\
\cline { 2 - 9 } & Sig. & 0 & 0,001 & & 0,006 & 0 & 0 & 0 \\
\hline \multirow{2}{*}{$\mathrm{EB}$} & $\begin{array}{l}\text { Pearson } \\
\text { Correlation }\end{array}$ &, $460^{*}$ &, $738^{* *}$ &, $528^{* *}$ & 1 &, $605^{* *}$ &, $872^{* *}$ &, $812^{* *}$ \\
\cline { 2 - 9 } & Sig. & 0,018 & 0 & 0,006 & & 0,001 & 0 & 0 \\
\hline \multirow{2}{*}{$\mathrm{EM}$} & $\begin{array}{l}\text { Pearson } \\
\text { Correlation }\end{array}$ &, $783^{* *}$ &, $695^{* *}$ &, $745^{* *}$ &, $605^{* *}$ & 1 &, $889^{* *}$ &, $849^{* *}$ \\
\cline { 2 - 9 } & Sig. & 0 & 0 & 0 & 0,001 & & 0 & 0 \\
\hline \multirow{2}{*}{$\mathrm{CI}$} & $\begin{array}{l}\text { Pearson } \\
\text { Correlation }\end{array}$ &, $698^{* *}$ &, $890^{* *}$ &, $748^{* *}$ &, $872^{* *}$ &, $889^{* *}$ & 1 &, $958^{* *}$ \\
\cline { 2 - 9 } & Sig. & 0 & 0 & 0 & 0 & 0 & & 0 \\
\hline \multirow{2}{*}{ GDP } & $\begin{array}{l}\text { Pearson } \\
\text { Correlation }\end{array}$ &, $810^{* *}$ &, $842^{* *}$ &, $871^{* *}$ &, $812^{* *}$ &, $849^{* *}$ &, $958^{* *}$ & 1 \\
\cline { 2 - 9 } & Sig. & 0 & 0 & 0 & 0 & 0 & 0 & \\
\hline
\end{tabular}

**. Correlation is significant at the 0.01 level (2-tailed).

*. Correlation is significant at the 0.05 level (2-tailed).

Source: author 


\section{REVIEW OF ECONOMIC PERSPECTIVES}

Table 8. Variability of NUTS 2 ranks

\begin{tabular}{|c|c|c|c|c|c|c|c|}
\hline \# of NUTS 2 & Cluster & $\bar{r}_{i}$ & $\sigma_{i}$ & $r_{i}^{\max }$ & $r_{i}^{\min }$ & $\bar{R}^{\min \max }$ & $\bar{R}^{\sigma}$ \\
\hline 26 & III & 1,00 & 0,06 & 1 & 1 & 0 & 0 \\
\hline 5 & III & 2,14 & 0,53 & 4 & 1 & 3 & 1 \\
\hline 4 & III & 3,38 & 0,97 & 7 & 1 & 6 & 2 \\
\hline 20 & II & 4,00 & 1,30 & 8 & 1 & 7 & 3 \\
\hline 12 & II & 6,58 & 1,85 & 15 & 5 & 10 & 4 \\
\hline 15 & II & 6,92 & 1,88 & 11 & 4 & 7 & 4 \\
\hline 8 & II & 7,89 & 2,57 & 15 & 4 & 11 & 5 \\
\hline 2 & II & 8,55 & 4,95 & 26 & 1 & 25 & 10 \\
\hline 16 & II & 8,85 & 2,13 & 12 & 1 & 11 & 4 \\
\hline 10 & II & 9,78 & 1,62 & 13 & 7 & 6 & 3 \\
\hline 13 & II & 11,03 & 2,57 & 16 & 6 & 10 & 5 \\
\hline 23 & II & 11,74 & 3,19 & 24 & 6 & 18 & 6 \\
\hline 18 & $\mathrm{I}$ & 11,96 & 2,96 & 20 & 5 & 15 & 6 \\
\hline 1 & $\mathrm{I}$ & 14,74 & 3,21 & 20 & 8 & 12 & 6 \\
\hline 14 & $\mathrm{I}$ & 14,94 & 1,61 & 17 & 9 & 8 & 3 \\
\hline 22 & $\mathrm{I}$ & 16,59 & 3,49 & 25 & 12 & 13 & 7 \\
\hline 11 & $\mathrm{I}$ & 16,78 & 2,37 & 24 & 13 & 11 & 5 \\
\hline 7 & $\mathrm{I}$ & 18,84 & 3,65 & 25 & 12 & 13 & 7 \\
\hline 21 & $\mathrm{I}$ & 19,32 & 1,66 & 22 & 17 & 5 & 3 \\
\hline 6 & $\mathrm{I}$ & 19,59 & 1,93 & 22 & 15 & 7 & 4 \\
\hline 9 & $\mathrm{I}$ & 20,24 & 3,02 & 25 & 13 & 12 & 6 \\
\hline 25 & $\mathrm{I}$ & 20,34 & 2,12 & 22 & 13 & 9 & 4 \\
\hline 17 & $\mathrm{I}$ & 22,24 & 2,62 & 24 & 14 & 10 & 5 \\
\hline 19 & I & 23,75 & 2,22 & 26 & 17 & 9 & 4 \\
\hline 3 & I & 24,06 & 2,27 & 25 & 18 & 7 & 5 \\
\hline 24 & $\mathrm{I}$ & 25,67 & 2,05 & 26 & 16 & 10 & 4 \\
\hline \multicolumn{6}{|c|}{ 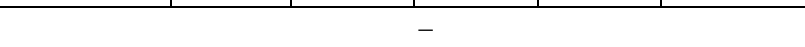 } & 0,62 & 0,83 \\
\hline
\end{tabular}

\section{Source: author}

